\title{
A casa própria e a locação social numa óptica urbanística e econômica
}

\author{
Home ownership and social rent from an urban and economic \\ perspective
}

\section{Propiedad de vivienda y arrendamiento social desde una perspectiva urbana y económica}

Recebido em 27/07/2020 Aceito em 13/11/2020

BEZERRA, Maria do Carmo de Lima ${ }^{1}$

MELLO, Cristina Maria Correia de ${ }^{2}$

\begin{abstract}
1 Universidade de Brasília, Faculdade de Arquitetura e Urbanismo, Programa de Pós-Graduação em Arquitetura e Urbanismo, Brasília, Brasil. mdclbezerra@gmail.com ORCID ID: 0000-0002-7736-5265
\end{abstract}

\footnotetext{
2 Universidade de Brasília, Faculdade de Arquitetura e Urbanismo, Programa de Pós-Graduação em Arquitetura e Urbanismo, Brasília, Brasil. mello_cmc@yahoo.com.br ORCID ID: 0000-0003-1153-9899
} 


\title{
Resumo
}

As políticas habitacionais praticadas no Brasil tratam a moradia como um bem de consumo, levando à estratégia de construção de unidades habitacionais e à ideia de provisão habitacional relacionada com a conquista da propriedade. Essa prática não tem conseguido suprir a necessidade de moradia social e tem levado à expansão urbana marcada pela dispersão, altos custos de infraestrutura e moradias desprovidas de serviços urbanos. No plano internacional, adota-se estratégias de locação de imóvel como um serviço prestado pelo Estado, modelo que atende à população dialogando com o estoque privado de imóveis em áreas urbanizadas, opção esta que o Brasil inicia com dificuldades de aceitação por parte dos agentes do governo e da sociedade. A questão colocada para investigação se refere aos custos financeiros, aos impactos urbanísticos e a qualidade da moradia que uma e outra modalidade de provimento habitacional poderiam representar na realidade brasileira. Como método utilizou-se os custos de implantação do PMCMV comparando-o com a quantidade de moradia capaz de rentabilizar a locação por 20 anos em áreas já urbanizadas no Distrito Federal. Como resultado se apresenta vantagens e desvantagens da casa própria e da locação social em relação aos custos e impactos urbanísticos para o Estado e a sociedade.

Palavras-Chave: Planejamento urbano; habitação de interesse social; locação social; Programa Minha Casa Minha Vida; casa própria.

\begin{abstract}
Housing policies practiced in Brazil treat housing as a consumer good, leading to the strategy of building housing units and the idea of housing provision related to the conquest of property. This practice has not been able to meet the need for social housing and has led to urban expansion marked by dispersion, high infrastructure costs and housing deprived of urban services. At the international level, property rental strategies are adopted as a service provided by the State, a model that serves the population in dialogue with the private stock of properties in urbanized areas, an option that Brazil begins with difficulties in acceptance by government agents and society. The question posed for investigation concerns the financial costs and urban impacts and the quality of housing that both types of housing provision could represent under Brazilian conditions. As a method, the costs of implementing the PMCMV were used, comparing it with the amount of housing capable of making the rental profitable for 20 years in already urbanized areas in the Federal District. As a result, there are advantages and disadvantages of homeownership and social rent in relation to urban costs and impacts for the State and society.
\end{abstract}

Key-Words: Urban planning; social interest housing; social rent; Minha Casa Minha Vida Program; own house.

\section{Resumen}

Las políticas de vivienda practicadas en Brasil a tratan como un bien de consumo, lo que lleva a la estrategia de construir unidades de vivienda y la idea de su provisión relacionada con la conquista de la propiedad. Esta práctica no ha logrado satisfacer la necesidad de moradas y ha llevado a la expansión urbana, los altos costos de infraestructura y los servicios deficientes. A nivel internacional, las estrategias de alquiler de propiedades se adoptan como un servicio proporcionado por el Estado, un modelo que sirve a la población en diálogo con el stock privado de propiedades en áreas urbanizadas. Brasil inicia esta modalidad con dificultad en la implementación. Ante este problema, la pregunta que se debe investigar se refiere a los costos, en Brasil, de atender la misma población a través de una modalidad y otra para la provisión de viviendas. Como método, se utilizaron los costos de implementación del PMCMV, comparándolo con la cantidad de viviendas capaces de rentabilizar el alquiler durante 20 años en áreas ya urbanizadas. Como resultado, existen ventajas y desventajas de la propiedad de vivienda y el arrendamiento social en relación con los costos e impactos urbanos para el Estado y la sociedad.

Palabras clave: Planificación urbana; vivienda de interés social; arrendamiento social; Programa Minha Casa Minha Vida; casa propia. 


\section{Introdução}

A temática habitacional se constitui em um dos maiores desafios da política urbana brasileira. Desde a primeira metade do século passado, todas as iniciativas de programas implementados pelos governos não lograram êxito na redução do déficit habitacional para as populações de baixa renda. A característica predominante da moradia, entre as várias ações do Estado sobre a crescente urbanização e suas consequências para a população, foi tratá-la como bem de consumo. O Estado passou a definir programas e ações para a construção de unidades habitacionais de interesse social destinadas à venda, estabelecendo a ideia de provisão habitacional diretamente relacionada com a conquista da propriedade. Criou-se a ideologia da casa própria, dificultando a utilização de outras possibilidades de provimento da moradia (BONDUKI, 2004; CARDOSO, 2013; ROLNIK, 2009 e MARICATO, 2011).

Este modelo de política pública tem esbarrado na dificuldade tanto em dispor de recursos de forma continuada para construção de casas e apartamentos para venda subsidiada quanto na garantia de moradia de qualidade. $O$ modelo patrocinado gerou a expansão urbana espraiada ${ }^{1}$, na forma de conjuntos habitacionais, muitas vezes, em áreas sem infraestrutura e sem os serviços necessários, produzindo uma periferia excluída dos benefícios urbanos.

Nesse contexto, se discute os reflexos dessa prática de produção habitacional no Brasil em comparação com outras estratégias de moradia, como a locação social. Utilizada em diversos países do mundo e de forma ainda incipiente no Brasil, essa modalidade de provimento habitacional, aparentemente, é capaz de diminuir o déficit habitacional de forma mais rápida e contínua e de produzir melhores cidades (MELLO e BEZERRA, 2019). Mas, por que a locação social é pouco utilizada no Brasil? Os custos da implantação de um Programa de locação social são os mesmos de um programa voltado para a casa própria? Na perspectiva da cidade e da qualidade de vida da população, quais as vantagens de um programa em relação ao outro? Essas são as questões que se procura responder nesse artigo.

Partindo do entendimento que a moradia não se constitui somente na edificação, mas também, no acesso à cidade se discute, ainda, os atributos que a integram e como eles comparecem na "casa própria" e na "casa alugada", observando as vantagens e desvantagens que cada modelo traz para a cidade e para a população. Para tal, foi considerado seus custos de implantação de forma a verificar quantas famílias é possível atender com moradia na forma de locação social utilizando os mesmos recursos gastos no provimento habitacional por um programa de casa própria, tomando como referência o último programa governamental sobre essa modalidade no Brasil, o Programa Minha Casa Minha Vida - PMCMV.

Como estudo de caso foi considerado o Distrito Federal - DF, adotando como exemplo para estudo econômico e urbanístico o Conjunto Habitacional do MCMV - Residencial Paranoá Parque. Foram contrapostos os custos e as características do conjunto com a locação social ofertada nas regiões de Taguatinga, Samambaia e Ceilândia, todas cidades consolidadas.

\section{Metodologia}

Para alcançar os objetivos propostos, a metodologia utilizada foi composta por três etapas: (i) estudo de alguns conceitos de forma a identificar os atributos da casa própria e da locação social, e como elas são/podem ser distribuídas na estrutura espacial das cidades; (ii) seleção do empreendimento a ser analisado, dentro do DF, que disponibiliza a casa própria para a população de baixa renda e a escolha dos locais da cidade a serem utilizados para seleção de imóveis para a locação social, quando foram considerados os atributos urbanísticos das duas opções; e (iii) realização dos cálculos do valor despendido para cada Unidade Habitacional - UH do MCMV e o posterior confronto desses com os valores de aluguel de imóveis para programas de locação social, relacionando quantas famílias são capa-

\footnotetext{
${ }^{1}$ Expansão urbana intercalada por extensos vazios.
} 
zes de serem atendidas, por programas de locação social, com o valor empregado na construção de casas próprias.

O critério para a escolha do empreendimento objeto de estudo se deu pelo fato dele ser o único conjunto implantado no DF, dentro do PMCMV do Governo Federal em parceria com o Governo do Distrito Federal, direcionado às famílias do Faixa $1^{2}$ do Programa. Quanto aos critérios para escolha dos imóveis para a locação social, foram selecionadas regiões consolidadas do ponto de vista urbanístico, ou seja, localizadas em áreas com serviços, equipamentos públicos e empregos e/ou localizadas em áreas dotadas de transporte coletivo de massa (metrô). Dessa forma, estaria privilegiando a concentração urbana, aspecto locacional determinante para moradia de qualidade, em detrimento da periferização.

Para o cálculo do valor total de cada UH do PMCMV foram considerados os custos do terreno, dos projetos, da infraestrutura e da construção. O valor do terreno foi informado pela Companhia Imobiliária de Brasília - Terracap e os custos dos projetos, infraestrutura e construção das UH's, foram confirmados pela Companhia de Desenvolvimento Habitacional do Distrito Federal - CODHAB. Para obter o valor atualizado do gasto total despendido com o MCMV à época, as despesas foram convertidas para dólar, utilizando a média anual do dólar no ano do orçamento.

Como forma de estimar o valor dos imóveis para locação buscou-se anúncios publicitários praticados no mercado de aluguel nas regiões pré-selecionadas, considerando imóveis com áreas semelhantes ao da unidade produzida pelo PMCMV. O valor do aluguel de cada região foi estabelecido a partir da média do aluguel de um número mínimo de 5 anúncios. Buscou-se para os cálculos os valores dos aluguéis mais baixos anunciados. Essa foi uma forma de cálculo que pode elevar os valores por se referir a uma expectativa de mercado, mas ela foi considerada mais realista. Outra seria levantar preço médio divulgado pela associação de corretores de imóveis, considerando os negócios de fato realizados. De qualquer forma, a diferença no mercado do DF não tem sido historicamente grande.

De posse desses resultados, procedeu a leitura considerando a óptica econômica e urbanística de cada estratégia habitacional estudada, simulando ainda, uma possibilidade de programa de locação social, tendo como objetivo demonstrar as vantagens e desvantagens de cada modalidade.

\section{Características das modalidades de provimento habitacional: casa própria e locação social}

Desde a década de 1940, quando ocorreram as primeiras intervenções do Estado no setor habitacional, as iniciativas variaram de medidas regulatórias como congelamento de aluguéis até programas habitacionais voltados para a produção de moradias para venda. As políticas públicas de construção de novas unidades, com a participação do Estado e da iniciativa privada, contribuíam para priorizar o direito de posse de um bem em detrimento do direito à cidade. Isso se deu porque os programas focam na edificação e não no acesso aos serviços que compõem o urbano.

O Estado buscava, pelas políticas públicas implementadas, a diminuição do déficit habitacional agravado devido ao contexto social e econômico do processo de urbanização à época. As ações empreendidas geraram uma aspiração crescente pela casa própria como a melhor opção, independentemente da localização e da qualidade das moradias produzidas. Segundo Bolaffi (1982), a casa própria tornouse o ideal das famílias brasileiras desde meados do século XX, sendo a fonte de status perante a sociedade e o bem de maior valor para a maioria das pessoas, dado os rumos insertos da economia, com a insegurança do emprego e/ou baixos salários e alta inflação.

Hoje, a Política Nacional de Habitação - PNH expressa no Plano Nacional de Habitação - PlanHab

${ }^{2} \mathrm{O}$ Faixa 1 do PMCMV atende famílias com renda de até $\mathrm{R} \$ 1800,00$. 
prevê outras possibilidades de obtenção de moradias que cobrem uma gama de alternativas que vão de preços mais reduzidos até a opção de localização, como: lotes urbanizados ${ }^{3}$; assistência técnica ${ }^{4}$ e locação social, ampliando os modelos de atendimento da população de baixa renda.

\subsection{A moradia como bem de consumo subsidiado pelo Estado}

Conforme Harvey (2013), o estímulo à aquisição de unidades habitacionais impulsiona moradoresusuários a se tornarem moradores-proprietários, sujeitando-se à lógica capitalista de produção. Entretanto, como visto, resta à população de menor renda ser um morador-proprietário de casas localizadas nas periferias das cidades devido ao alto valor da terra nas áreas mais centrais.

Produzidas nesse contexto, a habitação social - a conquista da casa própria - não é um direito à moradia e à cidade, mas sim um bem de consumo. Ela possui um valor financeiro para troca no mercado e possui, também, um significado cultural de ascensão social. Essa assertiva encontra amparo quando nos debruçamos sobre o conceito de bem de consumo.

Para a economia, os bens de consumo são todos os produtos a serem consumidos por indivíduos ou famílias, relacionados à satisfação das necessidades da população (DOUGLAS,2007). O consumo é essencialmente cultural e a sociedade moderna é caracterizada como uma sociedade de consumo. Isso significa admitir que o consumo está preenchendo, entre nós, uma função acima e além daquela de satisfação de necessidades materiais e de reprodução comum a todos os demais grupos sociais (BARBOSA, 2010).

Como visto, o caminho adotado no Brasil foi o de conceber a habitação como um bem de consumo por meio do modelo de construção da casa subsidiada. Isso levou a uma manipulação ideológica e sedutora da população, reforçando os sonhos e desejos celebrados no imaginário cultural de uma sociedade, pautada no "sonho da casa própria", em detrimento do direito à cidade.

O modelo "casa própria" analisado dentro do contexto urbanístico é uma estratégia que está sempre demandando terra para localização de novos conjuntos habitacionais, que só construídos em larga escala encontram alguma viabilidade financeira. Por isso, está sempre expandindo a cidade e incorrendo em altos custos aos cofres públicos, seja de implantação de infraestruturas e/ou sua manutenção. Assim, esse modelo tem dificultado o atendimento à necessidade habitacional da população e contribuído para baixa qualidade urbana.

Com custos altos, muitas vezes esses programas são interrompidos devido às prioridades estabelecidas pelos diferentes governos às políticas públicas. Segundo Paolinelli e Costa (2015), a falta de moradia para a baixa renda reflete um país desigual, onde os interesses privados sempre ficaram à frente dos interesses coletivos. As críticas também são feitas ao Estado, por ter sido omisso por muito tempo frente aos problemas habitacionais da população de baixa renda, que necessita de subsídios, tendo por outro lado, ao longo da história, períodos onde foram priorizados programas de financiamento para a classe média, dada sua rentabilidade. Dentro desse contexto é importante considerar o grande avanço do PMCMV na concessão de subsídios públicos para a faixa de menor renda; mesmo que mantidas as demais condições de definição locacional e de arranjo de execução a que foi referida anteriormente o tem propiciado a provisão de moradia de baixa qualidade.

\subsection{A moradia como um serviço prestado pelo Estado}

A locação social se fundamenta na ideia de prestação de um serviço pelo Estado ou desse em parceria com o setor privado, com o intuito de viabilizar a moradia à população de baixa renda. Essa moradia é

\footnotetext{
${ }^{3}$ Lotes urbanizados para fins habitacionais (Lei $\left.n^{\circ} 11.124 / 2005\right)$. Segundo o Decreto n³7.438/16 (Habita Brasília), os lotes urbanizados devem possuir toda infraestrutura necessária e estar localizado próximo aos centros de emprego e serviços públicos.

${ }^{4}$ Assistência técnica gratuita nas áreas de arquitetura, urbanismo e engenharia para os participantes de programas de habitação social beneficiados com recursos do FNHIS (Lei n 11.124/2005).
} 
fornecida, com aluguéis subsidiados, ou não, pelo poder público, sem a transferência de propriedade do imóvel, que pode ser público ou privado, para o beneficiário.

Para melhor entendimento de qual modalidade de aluguel se constitui em provimento de moradia pela locação social, se faz aqui uma caracterização das várias modalidades: (1) aluguel de mercado, tipo de locação onde as moradias fornecidas são de particulares, construída com dinheiro próprio e paga mensalmente com o dinheiro do salário dos inquilinos; (2) auxílio aluguel ou aluguel social, benefício assistencial temporário destinado a atender famílias em vulnerabilidade, não constituindo um provimento habitacional, mas sim uma ajuda social; e (3) locação social, ação do Estado, com ou sem parceria do setor privado, de forma a viabilizar a moradia à população de baixa renda, sem a transferência do imóvel, por meio de pagamento de um valor específico, subsidiado ou não, que diminua o comprometimento da renda familiar com a moradia. A moradia é entendida como um serviço fornecido pelo Estado.

Segundo Maher Júnior (2015), é preciso regulamentar e promover a prestação de um serviço de moradia livre das imperfeições e falhas da concorrência e da lógica de mercado. É nessa categoria que se inclui a locação social, sendo ela um serviço para garantir o direito à cidade e não uma assistência social ou um subsídio para aquisição de um bem.

Para a economia, serviços são atividades que criam valor e fornecem benefícios para clientes em tempos e lugares específicos, de acordo com a mudança desejada ou de acordo com a necessidade do destinatário do serviço (LOVELOCK e WRIGHT, 2001). Na visão dos economistas, tanto para os autores clássicos quanto para os contemporâneos ${ }^{5}$, os serviços sempre foram tratados como sendo um trabalho e o seu papel deve estar relacionado ao processo de geração de valor na economia (MARX, 1867; SAY, 1803). Serviço é um trabalho em processo e não o resultado da ação do trabalho, sendo a sua existência que garante a reprodução do capital, o que permite tratá-lo de forma integrada ao sistema econômico, mas com atributos diferenciados do de bem de consumo.

A locação de imóveis, considerando o pensamento de $\operatorname{Marx}^{6}$ (1867), por se dá em uma base capitalista de produção onde produz a atividade de moradia para família ou pessoa que não possui renda suficiente para adquirir o bem produzido, pode ser vista sim como um serviço que gera renda para o proprietário de um bem adquirido. Ela, também, pode ser entendida pelo pensamento dos economistas contemporâneos como um serviço onde, o bem alugado gera utilidade para o novo usuário, produzindo riqueza. A locação social pode ser considerada um serviço que, ao ser provido pelo Estado com fins de garantir moradia e acesso à cidade, gera benefícios para a população de baixa renda em tempos e lugares específicos, podendo ser interrompido ou não, de acordo com a necessidade dessa população.

A locação social vem sendo muito utilizada no plano internacional e traz, segundo estudos (DUJOLS, 2004; MELLO e BEZERRA, 2019; PEPPERCORN e TAFFIN, 2009), algumas vantagens como: (a) redução de custos para o Estado; (b) imóveis para aluguel com melhor localização na cidade e mix social; (c) por utilizar imóveis já existentes na cidade, consegue prover a moradia de forma mais rápida do que no modelo ‘casa própria`; (d) evita o espraiamento urbano; (e) possibilidade dos beneficiários escolherem local e tamanho da moradia, dentre os imóveis disponíveis; e (f) podem ser utilizados imóveis abandonados em áreas mais centrais e/ou vazios urbanos para a construção de moradias para aluguel mais bem localizadas.

\footnotetext{
${ }^{5}$ Autores clássicos são os teóricos situados no período que vai da metade do século XVIII e se estende ao longo do século XIX, como Adam Smith (1776), Jean Baptiste Say (1803), John Stuar Mill (1848), Karl Marx (1867) e Leon Walras (1874). A controvérsia entre estes autores em torno do conceito de trabalho produtivo e do papel desempenhado pelos serviços na dinâmica econômica fornece importantes contribuições a respeito do conceito de serviço. Ver Silva e Meirelles (2003).

${ }^{6}$ Segundo Marx (1867, vol II:101-2), todos os serviços cujo processo produtivo se dê em bases capitalistas de produção são considerados produtivos.
} 


\subsection{Atual situação da casa própria e da locação social no Brasil}

Apesar dos avanços, percebe-se que alternativas de provimento habitacional diferentes da casa própria são encaradas como paliativas e passageiras no Brasil. A ideologia da casa própria está 'entranhada' na sociedade, o que traz a dificuldade no desenvolvimento e implantação de alternativas de provimento habitacional, tanto na visão do Estado quanto da sociedade. Observa-se que a casa própria aparece como o sonho de qualquer brasileiro em detrimento do aluguel e que, essa vontade de se apropriar da mercadoria vem de uma cultura que só a propriedade dá segurança, dado a instabilidade econômica e política ao longo dos anos.

\subsubsection{O Programa Minha Casa Minha Vida - PMCMV}

Dando continuidade à linha iniciada na década de 1940 de provimento habitacional por meio da casa própria, o último Programa do Governo Federal - PMCMV manteve essa abordagem. Essa modalidade, como vista, integra a PNH, apesar de não ser a única, o que demonstra a grande dificuldade do poder público em rever as opções de políticas em relação à habitação.

Criado em 2009, o PMCMV estava vigente até recentemente, quando foi criado o Casa Verde Amarela pela MP996/2020 em agosto de 2020 que, ainda, não apresentou resultados para análise. Nesse sentido, o trabalho tomará como base o PMCMV que foi concebido pela Lei $n^{\circ} 11.977 / 2009$ com vistas a subsidiar a aquisição de moradia para famílias de baixa renda e, também, com o objetivo de estimular a construção civil (BONDUKI, 2009; CARVALHO et. ali, 2015).

O programa foi estruturado em faixas de renda para atendimento à população: (a) Faixa 1, famílias com renda mensal de até $R \$ 1800,00$; (b) Faixa 1,5: famílias com renda mensal entre $R \$ 1.801,00$ e $R \$ 2.600,00$; (c) Faixa 2, para famílias com renda mensal de $R \$ 2.601$ até $R \$ 4.000$; e (d) Faixa 3, famílias com renda entre $R \$ 4.001,00$ até $R \$ 9.000,00$. Os subsídios variam conforme a faixa de renda na qual se encontra o beneficiário.

Executado pela iniciativa privada com aporte do Governo Federal, o empreendedor necessitava demonstrar a viabilidade locacional da terra onde seriam construídas as habitações. Essa condição estava em sintonia com a Lei $n^{\circ}$ 10.257/2001 - Estatuto da Cidade para evitar a má qualidade da habitação verificada no passado. Entretanto, isso não ocorreu em vários municípios brasileiros, uma vez que, ao ser executado pela iniciativa privada, prevaleceu a máxima de que a terra quando já possui infraestruturas, acaba por ter um valor agregado mais alto. Outro ponto, para complicar essa equação é que, segundo Maricato (2011), nas periferias das grandes cidades os preços de terrenos dobraram após o lançamento do PMCMV.

Sendo a implantação do PMCMV a cargo das construtoras que se encontram atrelada às regras do mercado imobiliário o Programa contribuiu para: (a) segregação dos conjuntos habitacionais, levando à periferização da moradia; (b) fragmentação das cidades com criação de vazios urbanos; e (c) aumento do custo da construção das moradias do PMCMV devido à necessidade de instalação de novas infraestruturas e equipamentos.

Decorre da prática acima, a ampliação da dispersão urbana e exclusão social da população de baixa renda, que já era muito forte no país. A contradição de tudo isso é que o Programa repete experiências antigas sobre as quais já se havia produzido muitas reflexões, que por sua vez, foram insumos para a elaboração do Estatuto da Cidade, editado de forma contemporânea à criação do PMCMV. Autores como Rolnik (2009) e Maricato (2011), defendem a ideia que o Programa foi omisso na questão urbana. Destaca, ainda, que existem outras formas de prover moradia além da produção de novas unidades. Os vazios urbanos que existem nas cidades poderiam ser utilizados, assim como outras estratégias habitacionais, como a locação social. 


\subsubsection{Iniciativas de locação social}

No Brasil, a locação social apareceu no cenário como mecanismo de provimento habitacional constante da $\mathrm{PNH}$, com previsão de ser criada linha de financiamento destinado à produção de unidades habitacionais dirigidas à locação. Tal mecanismo surge como uma alternativa de provisão habitacional para a população de menor poder aquisitivo.

Mesmo a PNH englobando a locação social como um dos modelos de provisão de moradias, observase que essa opção ainda não foi alavancada de forma satisfatória no contexto nacional, demonstrando dificuldades no rompimento do ideal da casa própria. Atualmente, a locação como forma de provimento habitacional pode ser encontrada na legislação de poucos municípios brasileiros, dentre os quais: Santos, São Paulo, Campo Grande, Goiânia, Curitiba, Fortaleza, Belo Horizonte, Distrito Federal e Porto Alegre. Desses, apenas, no município de São Paulo ela foi implementada com as características de habitação social como um serviço público. Nos outros municípios e no DF, ela encontra-se ainda na forma de um programa, à exceção de Santos, onde ela já foi implementada, mas voltada mais à assistência social.

Por meio dos estudos realizados sobre a locação social (OLIVEIRA, 2009; TSUKUMO, 2007), algumas dificuldades foram observadas na sua implantação, como: (a) dificuldade de manter o Programa exclusivamente com recursos públicos para implantação do parque locatício e para fornecimento de subsídios, levando a problemas na sua sustentabilidade econômica; (b) excessiva responsabilidade de gestão para o município: elaboração do programa, construção, manutenção, seleção dos beneficiários e manutenção (de forma direta ou terceirizada); (c) atendimento a beneficiários sem renda ou com renda muito baixa (caso de São Paulo) devido aos custos altos de gestão e manutenção que ultrapassam os valores pagos pelos beneficiários; (d) o modelo de construção e gestão do parque locatício remete a características de provimento da casa própria; (e) falta de capacidade dos municípios com alguns que não possuem, sequer, um Plano Municipal de Habitação; e (f) visão distorcida da locação social muitas vezes confundida como uma ação voltada para a assistência social.

Na prática, no Brasil, as decisões do governo se voltam para atender aos interesses do mercado imobiliário e de seus interesses populistas. Dentro desse contexto tem-se mostrado mais interessante a construção da casa própria para a classe de baixa renda, independente dos custos sociais, econômicos e urbanísticos que uma modalidade pode trazer em relação à outra.

\section{Discussão no contexto do Distrito Federal: o PMCMV e a simulação de Pro- grama de Locação Social}

Com a finalidade de prover parâmetros aos gestores públicos que possam orientar nas escolhas de estratégias de provimento habitacional mais adequadas à realidade de cada contexto socioeconômico e urbano, serão observados os impactos econômicos da estratégia de construção de moradias e da estratégia de aluguel de moradias para a população de baixa renda no Brasil. A dimensão de recursos a serem utilizados em cada modalidade pode influenciar, juntamente com os critérios urbanísticos, na adoção de políticas públicas que contribuam com a qualidade socioespacial, ambiental e econômica da população em consonância com o Estatuto da Cidade.

Em Brasília, o único conjunto habitacional construído, voltado para o faixa 1 do PMCMV, é o Residencial Paranoá Parque, localizado na Região Administrativa do Paranoá - RA VII, a cerca de $19 \mathrm{~km}$ da Rodoviária do Plano Piloto. A região do Paranoá é formada basicamente pelas classes de renda média-baixa e baixa renda e possui na sua estrutura urbana comércio, serviços variados e equipamentos públicos como escolas, posto de saúde e hospitais. Segundo Pesquisa Distrital por Amostra de Domicílios - PDAD (Codeplan, 2018), cerca de 64\% da sua população ativa está empregada, mas somente $26 \%$ trabalha na própria RA. A maioria trabalha no Plano Piloto e usa o ônibus como meio de transporte. O Paranoá Parque, por sua vez, está localizado adjacente a cidade do Paranoá, constituindo uma 
periferia da cidade.

Criado em 2014, o Paranoá Parque possui uma área com poligonal de projeto de 143,3059ha, conectada por sistema viário ao tecido urbano da cidade do Paranoá, em conformidade com a legislação urbanística e ambiental vigente. Criou 133 unidades imobiliárias destinadas a residências, comércio, serviços, instituições ou equipamentos públicos, voltados a uma população estimada de 21.029 habitantes com renda de até $R \$ 1.800,00$. Possui 27 quadras residenciais, cada uma com cerca de 16 blocos de 4 pavimentos, perfazendo um total de $6.240 \mathrm{UH}$, com área de $46 \mathrm{~m} 2$ cada.

O residencial foi ocupado sem os equipamentos públicos, comércio e serviços. No início contava apenas com as edificações multifamiliares. A ligação viária com o Paranoá não significa, necessariamente, acesso aos equipamentos que lá existem, dado que, se faz necessário algum tipo de transporte, e esse é precário.

Para fins de cálculo da simulação dos custos, foram comparados os recursos utilizados para produção do Residencial Paranoá Parque, considerando os valores do terreno, dos projetos, da infraestrutura e da construção das edificações, com os recursos a serem utilizados na política de locação social, por 20 anos, utilizando imóveis de particulares disponíveis no mercado.

No caso da locação, simulamos, para efeito comparativo, um programa capaz de disponibilizar moradia com subsídio de $100 \%$, por um período de 20 anos, dentro das dimensões do faixa 1 do PMCMV. A habitação deve estar localizada em áreas consolidadas das cidades, adjacentes a serviços e próximas ao transporte de massa, e deve prever a possibilidade de mudança de endereço/imóvel dentro do mesmo perfil habitacional para os beneficiários do Programa. Para efeito de formação de preço, foram escolhidas 3 regiões distintas do DF: Taguatinga, Samambaia e Ceilândia, regiões com faixas de renda aproximadas a da população alvo, mas que possibilitam o mix social. Essas regiões são dotadas de serviços, infraestrutura, equipamentos públicos e transporte em massa, capaz de favorecer a conquista do direito à cidade para a população de baixa renda. Figura 1.

Figura 1: Localização das áreas do PMCMV e da Locação social dentro do DF.

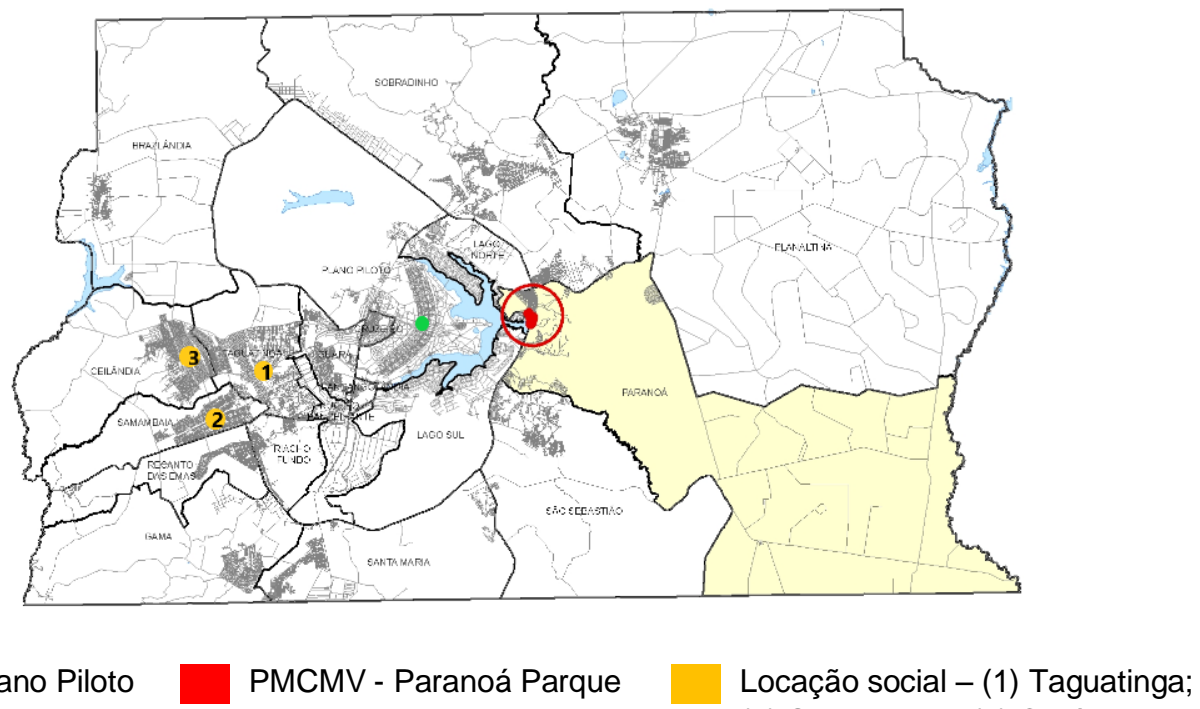

(2) Samambaia; (3) Ceilândia.

Fonte: Edital Concurso Público Paranoá Parque (2020), formatado pelas autoras

\subsection{Cálculo do custo da casa própria: o Residencial Paranoá Parque em Brasília}

Considerando os valores do terreno, dos projetos, da infraestrutura e da construção das edificações foi obtido o custo total para a implantação do Paranoá Parque. 


\subsubsection{Cálculo do valor do terreno}

A área para a construção do empreendimento foi doada pela Terracap, em 2013, para a CODHAB, responsável pela implantação das políticas habitacionais no DF dentro do Programa Habita Brasília, que representa o PMCMV no DF. À época, não foi feita uma avaliação da gleba, mas sim, dos lotes do parcelamento destinados à habitação multifamiliar, fornecendo um valor total de $\mathrm{R} \$ 51.804 .300,00$, valor considerado como custo total da área ${ }^{7}$.

Valor do terreno.

$\mathrm{R} \$ 51.804 .300,00$

\subsubsection{Custo projetos e obras do Residencial Paranoá Parque}

Segundo dados fornecidos pela CODHAB, cada UH, computando projetos, infraestruturas e construções ficou no valor final de $\mathrm{R} \$ 65.000,00 / \mathrm{UH}^{8}$. O Residencial conta com $6240 \mathrm{UH}$. Equação (1).

$\mathrm{V}=\mathrm{Vuh} \times \mathrm{Nuh}$

Onde:

V: valor total projetos e obras;

Vuh: valor da unidade habitacional;

Nuh: número de unidades habitacionais.

Valor total (projetos + obras)

$\mathrm{R} \$ 405.600 .000,00$

Como o valor do terreno e dos projetos e obras do Paranoá Parque são antigos, datados de 2013 e de 2012, respectivamente, os custos de cada item foi transformado em dólar, de acordo com a Tabela 1. No ano de 2012 a média anual do dólar foi de $U \$ 1,956$, em 2013 foi de U\$2,157 e em 2020, considerando a média até o mês de março, foi de $U \$ 4,457^{9}$.

Tabela 1: Custo total para implantação do Residencial Paranoá Parque.

\begin{tabular}{lll}
\hline CUSTOS & VALOR EM R\$ & $\begin{array}{l}\text { VALOR EM U\$ (̇́ ÉPOCA) } \\
\text { (Valor em R\$/valor do dólar) }\end{array}$ \\
\hline Terreno & $51.804 .300,00$ & $24.016 .828,93$ \\
\hline Projetos + obras & $405.600 .000,00$ & $207.361 .963,19$ \\
\hline VALOR TOTAL & $457.404 .300,00$ & $231.378 .792,12$ \\
\hline
\end{tabular}

Fonte: CODHAB e www.wimoveis.com.br

Segundo a Lei do PMCMV, para programas do faixa 1, o governo subsidia $90 \%$ do valor total do imóvel e os beneficiários arcam com $10 \%$ do valor total. Para fins desse estudo, será considerado o valor total da obra, já que na locação social, o valor do subsídio dependerá das regras a serem estabelecidas por cada programa, podendo variar de acordo com fatores, como: renda da população atendida, condições do mercado de trabalho, condição orçamentária do governo e até contexto político do momento.

\subsection{Simulação custo da locação social}

Investigou-se o valor de imóveis para locação em áreas de cidades já consolidadas, com renda média semelhante ou superior à da região onde localiza-se o Paranoá Parque, providas de equipamentos públicos, serviços e infraestrutura e próxima a acesso a transporte coletivo em massa (metrô), mesmo que estejam mais distantes da zona mais central, que é Brasília (marco zero: Rodoviária do Plano Pilo-

\footnotetext{
${ }^{7}$ Essas informações foram prestadas pela Terracap, com base no Processo n¹00.001.911/2013, em consulta realizada por telefone em março/2020.

${ }^{8}$ Dados do ano de 2012, fornecidos pela CODHAB, constantes no Processo $n^{\circ}$ 030.008.403/1999.

${ }^{9}$ Os valores do dólar foram obtidos pelo site: http://www.acinh.com.br/servicos/cotacao-dolar
} 
to). Aqui vale um destaque para as especificidades urbanísticas do DF, constituído por diferentes cidades sem formar uma só malha urbana.

As áreas selecionadas foram: (i) Taguatinga - RA III, uma das regiões mais ricas do DF, afora Brasília. Está localizada a cerca de $26 \mathrm{~km}$ da Rodoviária do Plano Piloto e possui um importante centro comercial, infraestrutura, empregos, serviços, e equipamentos públicos além da linha do metrô, o que facilita a mobilidade da população; (ii) Samambaia - RA XII: é dotada de infraestrutura e serviços, mas tem poucos equipamentos públicos, principalmente escolas. Sofreu, nos últimos anos, um intenso processo de urbanização, com a construção de grandes empreendimentos residenciais, atraindo a classe média para a região, dado existirem áreas urbanizadas e, ainda, não ocupadas e possuir acesso ao metrô. Possui muitos apartamentos para aluguel e está localizada a $31 \mathrm{~km}$ da Rodoviária do Plano Piloto; e (iii) Ceilândia - RA IX: é uma das principais regiões do DF, possui uma economia voltada principalmente para a indústria e o comércio. Localiza-se a cerca de $31 \mathrm{~km}$ da Rodoviária do Plano Piloto e é dotada de infraestrutura, serviços e equipamentos públicos essenciais além de transporte em massa (metrô).

Os valores dos imóveis em cada região analisada foram obtidos por meio de anúncios, utilizando sites comerciais de aluguel de imóveis disponíveis na internet ${ }^{10}$. Para a análise, foram empregados valores de anúncios de apartamentos de 2 quartos com áreas semelhantes a das UH do PMCMV. Para cada região, foram considerados no mínimo 5 anúncios, selecionando os valores mais baixos disponibilizados. Foi realizada a média dos valores considerados, obtendo o valor médio por região analisada de acordo com a Tabela 2.

Tabela 2: Valores médios para locação de UH de 2 quartos nas áreas estudadas.

\begin{tabular}{lll}
\hline REGIÕES & Valor médio aluguel (R\$) - Ap. 2 quartos & Metragem dos imóveis (m2) \\
\hline Taguatinga & 635,00 & 40 a 75 \\
\hline Samambaia & 660,00 & 45 a 50 \\
\hline Ceilândia & 698,00 & 45 a 67 \\
\hline
\end{tabular}

Fonte: www.wimoveis.com.br, formulado pelas autoras (2020)

Diante dos valores do aluguel nas regiões estudadas, foram calculados os custos a serem despendidos em 12 meses ( 1 ano) e no período de 240 meses (20 anos). Como forma de conduzir a análise, os valores obtidos pelo período de 20 anos foram transformados em dólar, com o objetivo de comparar com os valores totais do PMCMV. Posteriormente, utilizando os valores em dólar, foi calculado quantas UH's poderiam ser disponibilizadas pelo prazo de 20 anos de aluguel, utilizando o valor gasto para produzir as UH's no PMCMV e tendo como modelo o Paranoá Parque. Tabela 3.

Tabela 3: Número de UH de 2 quartos alugadas por 20 anos (utilizando o mesmo custo do PMCMV).

\begin{tabular}{llllll}
\hline REGIÃO & $\begin{array}{l}\text { Média Aluguel } \\
\text { ap. 2 quartos } \\
\text { (R\$) }\end{array}$ & $\begin{array}{l}\text { Aluguel/ano } \\
\mathbf{( R \mathbf { S } )}\end{array}$ & $\begin{array}{l}\text { Aluguel em } \\
\mathbf{2 0} \text { anos (R\$) }\end{array}$ & $\begin{array}{l}\text { Aluguel por } \\
\mathbf{2 0} \text { anos (U\$) }\end{array}$ & $\begin{array}{l}\text { UH total em 20 anos } \\
\text { (valor em U\$) }\end{array}$ \\
\hline Taguatinga & 630,00 & $7.560,00$ & $151.200,00$ & $33.924,16$ & 6.820 \\
\hline Samambaia & 650,00 & $7.800,00$ & $156.000,00$ & $35.001,12$ & 6.610 \\
\hline Ceilândia & 620,00 & $7.440,00$ & $148.800,00$ & $33.385,68$ & 6.930 \\
\hline
\end{tabular}

Fonte: www.wimoveis.com.br, formulado pelas autoras (2020)

Analisando os dados obtidos, verifica-se que, com o mesmo valor utilizado na construção das 6.240 UHs do PMCMV (U\$231.378.792,12), é possível atender com a locação social, em um período de 20 anos, mais famílias do que no PMCMV, em lugares providos de infraestrutura, serviços e dotados de transporte público em massa. Conforme pode ser visualizado na tabela 4, em Taguatinga atenderia

\footnotetext{
${ }^{10}$ Foi utilizado o site comercial www.wimoveis.com.br.
} 
6.820 famílias, em Samambaia seriam 6.610 famílias e na Ceilândia 6.930 famílias, isso considerando $100 \%$ de subsídio do governo para o Programa de Locação Social. Todos os apartamentos utilizados no cálculo da locação estão localizados, no máximo, até duas quadras da estação do metrô.

Nesse caso, cada família ainda teria poupado $10 \%$ do valor utilizado no PMCMV que, sem fazer as correções, seria um valor médio de $R \$ 15.000,00$ (quinze mil reais) afora outros gastos mensais que faria em uma área de menor acesso a serviços e transportes, sem contar outros atributos de integração social e urbanística que poderiam ser monetarizados, aumentando as vantagens financeiras da locação social.

Tabela 4: Número de UH para locação social em cada região analisada(utilizando o mesmo custo do PMCMV).

\begin{tabular}{llll}
\hline & Localização & $\begin{array}{l}\text { Número UH } \\
\text { (N famílias beneficiadas) }\end{array}$ & Custo provimento habitacional \\
\hline Casa própria & Paranoá Parque & 6.240 \\
\hline \multirow{2}{*}{ Locação social } & Taguatinga & 6.820 & \multirow{2}{*}{ U $\$ 231.378 .792,12$} \\
\cline { 2 - 3 } & Samambaia & 6.610 & 6.930 \\
\cline { 2 - 3 } & Ceilândia & 6.930 \\
\hline
\end{tabular}

Fonte: Formulado pelas autoras (2020)

Outro exercício de programa de locação social foi realizado. Considerou uma simulação hipotética, onde tem-se como diretriz básica o atendimento a famílias que se encontram em déficit habitacional por ônus excessivo com aluguel ${ }^{11} \mathrm{e}$ utilizando os mesmos critérios anteriores, ou seja, imóveis de particulares já existentes no mercado e disponíveis para locação ${ }^{12}$, mas agora com a utilização de um subsídio de $90 \%$ do valor total do aluguel pelo período de 20 anos (mesmo subsídio fornecido para o faixa 1 do PMCMV). Nesse caso, o governo conseguiria atender: 7.578 famílias com imóveis localizados em Taguatinga; 7.345 famílias com imóveis localizados em Samambaia ou 7.700 famílias com imóveis localizados na Ceilândia, ou seja, 1.338 famílias, 1.105 famílias ou 1.460 famílias, respectivamente, a mais do que o número de atendimento do PMCMV.

Ressalta-se, porém, que o cenário deste comparativo representa apenas um dos parâmetros para a escolha dos imóveis (apartamentos de 2 quartos). Outros modelos poderiam ser seguidos e o número e o valor total de UHs poderiam ser maiores. Como exemplo, tem-se: (i) escolha de imóveis em mais de uma região da cidade, a depender da necessidade das famílias a serem beneficiadas; e (ii) maior mescla da tipologia dos imóveis (imóveis de 1, 2 ou 3 quartos), de forma a atender diversos padrões de famílias.

Outros fatores a serem definidos no programa, a depender da estratégia traçada por cada política de locação, também são capazes de interferir na simulação dos dados. A exemplo, temos: (i) cada programa de locação produzido poderá ter um público alvo específico: atendimento a idosos; atendimento das famílias em ônus excessivo com aluguel; moradores de rua, dentre outros; (ii) o valor do subsídio a ser fornecido para as famílias de baixa renda; (iii) valor diferente de anos de locação, tanto para maior como para menor (15 ou 25 anos), de acordo com a faixa de renda ou de idade do beneficiário. Por fim, vale ressaltar que, para efeitos de cálculo, não foram considerados fatores que interferem nos custos do Programa como: (a) manutenção das edificações, onde a qualidade dos materiais utilizados para a construção vai interferir na sua manutenção; (b) despesas de condomínio, água e luz, apesar de presentes nas duas estratégias de moradia; e (c) valores destinados à gestão das unidades habitacionais de locação social, que podem ser geridas pela secretaria de habitação do município ou por empresas terceirizadas.

\footnotetext{
${ }^{11}$ Famílias em ônus excessivo por aluguel são aquelas onde mais de $30 \%$ da sua renda familiar é dispensada para o pagamento do aluguel da moradia.

${ }^{12}$ Disponíveis para locação pelo site www.wimoveis.com.br .
} 
É primordial observar que, na locação social, a mobilidade devido a possibilidade de alteração de moradia viabiliza a possibilidade da habitação perto das necessidades da família: perto de trabalho ou escola, proporcionando, uma maior apropriação da cidade frente à modalidade de construção da casa própria.

\section{Conclusão}

A produção de moradias para a baixa renda é um processo complexo que exige a participação do estado e grandes investimentos, sendo capaz de impactar, a depender das estratégias adotadas, positivamente ou negativamente a cidade e por consequência a população. No Brasil, ao longo dos anos ela vem sendo abordada pelo poder público como um bem de consumo - a casa própria, em detrimento do modelo de oferta de um serviço - a locação. Os resultados têm sido negativos em vários aspetos seja no atendimento do déficit e na qualidade da moradia quanto no tipo de cidade que tem contribuído para produzir.

Apesar de alguns avanços trazidos pelo Estatuto da Cidade, observamos, a partir do aprendizado do PMCMV, que as antigas práticas persistem. A aliança formada com os interesses mercadológicos por meio das construtoras levou a que, na maioria das vezes, a moradia fosse implementada afastada da mancha urbana, trazendo ônus inevitável para os moradores, para a cidade e para o poder público. Esses espraiamentos acarretam mais custos que decorrem de uma maior demanda por novas infraestruturas e equipamentos públicos em áreas afastadas, em detrimento da subutilização de toda estrutura já existente nos vazios urbanos.

Pela óptica urbanística, ao compararmos a estratégia de construção de casas do PMCMV com a locação social, observamos panoramas urbanos desiguais. Os empreendimentos do PMCMV voltados para a Faixa 1, geralmente monofuncionais e sem diversidade social, são inseridos nas áreas periféricas, longe de serviços e equipamentos públicos por possuírem terras com valores mais baixos e, muitas vezes, sem infraestrutura básica. Em contrapartida, as unidades para locação social, simuladas pelo presente estudo em áreas mais centrais da cidade, com toda infraestrutura instalada, serviços e próximas ao transporte público, apresentaram custos semelhantes para um mesmo número de famílias atendidas. Adiciona-se o fato dessa moradia responder melhor aos desejos das famílias que pode, ao longo dos anos, associar localização e tamanho às suas necessidades.

Dessa forma, a exemplo do que ocorre na experiência internacional, o provimento da moradia por meio da locação social é uma forma de garantir uma boa inserção urbana da população de baixa renda conforme as necessidades de cada família, diminuindo a segregação social e a guetização. O mix social favorece a inclusão de classes menos abastadas na cidade e, a localização das moradias em áreas dotadas de transporte, serviços e equipamentos públicos essenciais, é uma grande vantagem da locação social em detrimento da casa própria.

No Residencial Paranoá Parque isso é bem visível. Mesmo ele estando conectado por um sistema viário a uma cidade pré-existente, a cidade do Paranoá, o estudo demostrou que o poder público teve que arcar com todos os custos de infraestrutura e equipamentos básicos para a nova área residencial. Construir habitação social afastada da mancha urbana, apesar do valor da terra ser mais baixo, traz um ônus inevitável para os moradores e para o poder público. Para a manutenção da cidade são custos continuados de provimento dos serviços e não só de sua implantação, com os agravantes sobre as condições ambientais da cidade, com aumento do percentual de áreas impermeabilizadas. Do ponto de vista da população é alto o custo social representado com o deslocamento de longas distâncias por um longo tempo, para usufruir da cidade.

Considerando a óptica econômica referenciada na utilização de uma estratégia e outra, percebe-se que a mesma quantia despendida para a casa própria, fornecendo o mesmo subsídio de $90 \%$, poderia 
atender, em um período de 20 anos, mais de 1100 famílias com moradias por meio da locação social na região de Taguatinga, Samambaia ou Ceilândia. É um número bem representativo ao considerar valores gastos na construção de um único conjunto habitacional para a Faixa 1 e nos benefícios que traria para mais de mil famílias.

Os resultados obtidos apontam para a necessidade de estratégias governamentais dispostas a mudar a relação da moradia social com a produção da urbes. A habitação precisa ser pensada como uma peça fundamental do direito de morar e de acesso à cidade, sem distinção de classe social. É preciso construir cidades que gerem qualidade de vida para seus usuários, sendo necessário observar, além do quantitativo de habitações, os custos e a qualidade das moradias e das cidades produzidas, onde, os objetivos econômicos não podem sobressair aos habitacionais.

\section{Referências Bibliográficas}

BARBOSA, Lívia. Sociedade de consumo. 3ed. Rio de Janeiro: Zahar, 2010.

BONDUKI, Nabil Georges. Origens da Habitação Social no Brasil. 4aㅡ edição. São Paulo: Estação Liberdade, 2004.

BONDUKI, Nabil Georges. Do Projeto Moradia ao Programa Minha Casa, Minha Vida. Teoria e Debate. n. 82, p. 08-14, maio/junho 2009.

BOLAFFI, Gabriel. Habitação e urbanismo: o problema e o falso problema. In: MARICATO, Ermínia (Org.). A produção capitalista da casa (e da cidade) no Brasil Industrial. Prefácio de Francisco de Oliveira. 2.ed. São Paulo: Alfa-omega, 1982. 116p., cap. 2, p. 37-70, il. (Coleção Urbanismo).

CARDOSO, Adauto Lucio e outros. O Programa Minha Casa Minha Vida e seus Efeitos Territoriais. Editora Letra Capital. Observatório das Metrópoles. Rio de Janeiro, 2013.

CARVALHO, Caio Santo Amore de; SHIMBO, Lúcia Zanin; RUFINO, Maria Beatriz Cruz. Minha casa e a cidade? avaliação do programa minha casa minha vida em seis estados brasileiros. [S.I: s.n.], 2015. Disponível em:https://repositorio.usp.br/item/002725013. Acesso em fev/2020

CODEPLAN. Pesquisa Distrital por Amostra de Domicílios - PDAD. GDF. Brasília: Codeplan, 2018.

DOUGLAS, Mary. O mundo dos bens, vinte anos depois. Horizontes Antropológicos, Porto Alegre, ano 13, n.28, p. 17-32, jul/dez. 2007.

DUJOLS, Dominique et d'autres. Le logement dans la de centralisation. Référentiel Commun Associations de Collectivités Locales - HLM. Le union sociale pour I'habitat. Paris. 2004.

HARVEY, David. Os limites do capital. São Paulo: Boitempo, 2013.

LOVELOCK, Christophe; WRIGHT, Lauren. Serviços: marketing e gestão. São Paulo: Saraiva, 2001.

MAHER JÚNIOR, James. Instrumentos de financiamento a programas habitacionais de locação social: desafios e oportunidades. $141 \mathrm{f}$. Dissertação(Mestrado em Engenharia Urbana) - Setor de Engenharia Urbana, Universidade Federal do Rio de Janeiro. Escola Politécnica, Rio de Janeiro, 2015.

MARICATO, Ermínia. Impasse da política urbana no Brasil. Petrópolis: Vozes, 2011.

MARX, Karl (1867). O Capital. São Paulo: Ed. Nova Cultural, 1996.

MELLO, Cristina e BEZERRA, Maria do Carmo. Contribuição para o provimento da moradia por locação social: o que aprender com a experiência internacional. Revista Guaju, v.5, n.2, p. 30-41, jul/dez. Matinhos. 2019. 
OLIVEIRA, Glaucia. Gestão e vivências de velhices nas Repúblicas de Idosos de Santos. São Paulo, 2009, 153 p. Dissertação de Mestrado em Antropologia Social da Faculdade de Filosofia, Letras e Ciências Humanas da Universidade de São Paulo.

PAOLINELLI, Marina e COSTA, Rafaela. Políticas de locação social em experiências Internacionais. 2015. Projeto final de Graduação. Faculdade de Arquitetura e Urbanismo. UFMG. 2015.

PEPPERCORN, Ira; TAFFIN, Claude. Social housing in the USA and France: Lesson from convergences and divergences. Urban Planning International. 2009.

ROLNIK, Raquel. Mercantilização do espaço urbano e suas implicações na concepção de Cidades Justas, democráticas, inclusivas e humanas. Revista de Direito da Cidade, vol.11, n¹. pp.418-442. UERJ, 2009. Disponível em: https://www.e-publicacoes.uerj.br/index.php/rdc/article/view/35827/27998. Acesso em: fevereiro/2020.

SAY, Jean-Baptiste (1803). Tratado de Economia Política. São Paulo: abril Cultural, 1983.

TSUKUMO, I. T. L. Habitação Social no Centro de São Paulo: legislação, produção, discurso. São Paulo, 2007, 201 p. Dissertação de Mestrado - Faculdade de Arquitetura e Urbanismo da Universidade de São Paulo.

\section{Maria do Carmo de Lima Bezerra}

Arquiteta e urbanista, Profa. Titular da FAUUnB atuando na graduação e pós-graduação. Meste em Planejamento Urbano, 1988; Doutora pela FAUUSP,1996 com pós doutorado na AAP, Cornell University,2009 e ESTAM, Politécnico de Madri, 2019. Líder do Grupo de Pesquisa em Gestão Ambiental Urbana CNPQ/UNB e Pesquisador Produtividade do CNPQ . Possui diversos artigos em periódicos nas temática de politica urbana, infraestrutura e regularização fundiária. É revisora de diversos periodicos e consultora ad hoc do CNPQ. Exerceu diversas funções públicas com destaque para coordenação da Agenda 21 brasileira e do Zoneamento Econômico Ecológico no Ministério do Meio Ambiente e Secretária de Estado de Meio Ambiente no DF. Foi consultora em projetos urbanos/ambientais no BID e Banco Mundial. Em 2020, publicou pela Editora da Universidade de Brasília o livro "O que avançou na regularização fundiária". No prelo o livro "Paisagem Urbana-Natureza e Pessoas". É conselheira, Conselho de Planejamento Urbano do Distrito Federal.

Contribuição de autoria: Concepção, Análise, Metodologia e Redação - revisão e edição.

\section{Cristina Maria Correia de Mello}

Graduada em Arquitetura e Urbanismo pela UnB e doutoranda em Arquitetura e Urbanismo, na área de Projeto e Planejamento Urbano, no PPG-FAU/UnB. É Analista de Planejamento Urbano e Infraestrutura, atualmente atuando na Secretaria de Estado de Gestão do Território e Habitação do Distrito Federal. Participa do Grupo de Pesquisa Gestão Ambiental Urbana CNPQ/UNB com o projeto "Contribuição dos Instrumentos Urbanísticos à Política Habitacional". Atua como pesquisadora nas áreas de planejamento urbano e regional, habitação, paisagem urbana e mobilidade.

Contribuição de autoria: Concepção, Análise, Metodologia e Redação - rascunho original

Como citar: BEZERRA, Maria do Carmo de Lima; MELLO, Cristina Maria Correia de. A casa própria e a locação social numa óptica urbanística e econiomica. Revista Paranoá.n. 29, Jan/jun de 2021. DOI 10.18830/issn.1679-0944.n29.2021.09

Editores responsáveis: Gabriela Tenório, Rômulo Ribeiro e Carolina Pescatori. 